\title{
Del sonido del Pueblo a los ecos del pasado. Las versiones de La pasión según Trelew, de Tomás Eloy Martínez (1973-2009)
}

\author{
From the Sound of the People to the Echoes of the \\ Past. The Versions of La pasión según Trelew, by \\ Tomás Eloy Martínez (1973-2009)
}

\begin{abstract}
Resumen
La pasión según Trelew ocupa un lugar paradójico en la obra de Tomás Eloy Martínez. Por un lado, es el libro que le cambió la vida al autor, según él mismo lo ha descrito, y el único cuyo proceso de escritura atravesó prácticamente todas las etapas de su producción literaria: apareció originalmente en 1973 y fue reeditado en 1997 y 2009, cada vez con variaciones textuales introducidas por el autor. Por otro lado, el libro parece constituir la cristalización de una concepción de la escritura, sustentada en la confianza en los absolutos y en la confrontación militante entre lo verdadero y lo falso, de la que el escritor buscó distanciarse en momentos ulteriores de su trayectoria. En este artículo nos proponemos analizar el modo en que ese desplazamiento se inscribe en las distintas versiones del libro. Veremos que las versiones de 1997 y 2009 tienden a diluir la confrontación entre verdad y mentira que inicialmente daba forma al relato de los hechos ocurridos en Trelew en 1972. Asimismo, las reescrituras le restan protagonismo al Pueblo como sujeto colectivo que proveía fundamento a la confrontación entre verdad y mentira organizadora del texto.
\end{abstract}

Palabras claves

versión, verdad, literatura testimonial, documento, historia.

\begin{abstract}
La pasión según Trelew occupies a paradoxical place in the work of Tomás Eloy Martínez. On the one hand, it is the book that changed the author's life, as he himself has described it, and
\end{abstract}


the only one whose writing process went through practically all the stages of his literary work: it originally appeared in 1973 and was re-edited in 1997 and 2009, each time with textual variations introduced by the author. On the other hand, the book seems to constitute the crystallization of a concept of writing, based on trust in absolutes and on the militant confrontation between the true and the false, from which the writer sought to distance himself in later on his career. In this article, we propose to analyze the way in which this displacement is reflected in the different versions of the book. We will see that the versions of 1997 and 2009 tend to dilute the confrontation between truth and falsehood that initially shaped the account of the events that took place in Trelew in 1972. Likewise, the rewritings detract from the People's role as a collective subject that provided the basis for the confrontation between truth and lie that organized the text.

Keywords version, truth, testimonial literature, document, history.

\section{Introducción}

La pasión según Trelew ocupa un lugar paradójico en la obra del escritor y periodista argentino Tomás Eloy Martínez. Por un lado, es el libro que le cambió la vida al autor, según él mismo lo ha descrito (Martínez, La pasión 11 [1973]), y el único cuyo proceso de escritura atravesó prácticamente todas las etapas de su producción literaria: apareció originalmente en 1973 y fue reeditado en 1997 y 2009, cada vez con variaciones textuales introducidas por el autor. (La analogía con la experiencia de escritura y reescritura de Operación masacre, de Rodolfo Walsh, es aquí ineludible). ${ }^{1}$ Por otro lado, el libro parece constituir la cristalización de una concepción de la escritura de la que el escritor buscó distanciarse en momentos ulteriores de su trayectoria, a un punto tal que en los años 90 llegaría a afirmar: " $L a$ pasión según Trelew me parece la obra de otra persona, de alguien que ya no soy" (14-15).

Quizás debido a esta ubicación paradójica en la obra de Martínez, La pasión según Trelew no se ajusta sin más a las claves de lectura que la crítica ha construido en relación con los textos del autor. Estas suelen centrarse en las exploraciones que

\footnotetext{
${ }^{1}$ Walsh introdujo numerosas variaciones en el texto de Operación masacre luego de su publicación original como libro en $1957 \mathrm{y}$ en diversas reediciones aparecidas hasta la primera mitad de los años 70. Sobre este tema, véase Hernaiz, Louis ("Por qué escribir"), Puente y David, y nuestro propio estudio (García, "Las reescrituras").
} 
CATEDRAL TomAda: Revista de crítica literaria latinoamericana / Journal of Latin American Literary Criticism Del sonido del Pueblo a los ecos del pasado. Las versiones de La pasión según Trelew, de Tomás Eloy Martínez (1973-2009)

se despliegan en su obra narrativa en torno de los límites difusos entre novela e historia, entre hechos y ficción, entre mito y realidad social y política. ${ }^{2}$ Aunque estas lecturas resultan relevantes cuando se trata de los dos textos más célebres del escritor, La novela de Perón (1985) y Santa Evita (1995) -en los que ha tendido a concentrarse la crítica interesada por la narrativa de Martínez-, no ocurre lo mismo si se revisa un texto temprano como La pasión según Trelew. Tal como fue concebido en 1973 , este texto, de fuerte impronta documental o testimonial, ${ }^{3}$ no promueve una difuminación de los límites entre ficción y realidad, o entre novela e historia. Más bien por el contrario, introduce un contraste firme entre verdad y mentira, que se encuentra en la base de la aproximación del autor a los hechos ocurridos en Trelew en 1972 (Bonano 84, Zuffi 29).

En un ensayo de 2004, Martínez procura situar en perspectiva diacrónica la discusión sobre los vínculos entre novela e historia, que atraviesa buena parte de su obra:

Escribir hoy novelas sobre la historia es una operación que difiere, en más de un matiz, de los ejercicios narrativos de los años '60 y '70. En aquellas décadas de certezas absolutas, de posiciones netas, de cuestionamientos políticos y subversiones contra el poder o sumisiones al poder, la novela y la historia se movían dentro de un campo de tensiones en el cual los

${ }^{2}$ Ferro señala en este sentido que la obra de Martínez "desmonta la seguridad del orden binario" constituido en torno a las dicotomías historia/ficción, novela/autobiografía, investigación documental/imaginación libre (300). Minay inserta la narrativa del autor dentro de una tendencia posmoderna, en la que la novela se confunde con la crónica y la historia (13). Zuffi afirma, por su parte: "No se sabe dónde empieza el trasfondo histórico, lo testimonial y dónde lo imaginario, lo mágico, lo inverosímil en la producción narrativa de Martínez" (135). Vincenti, más recientemente, sostiene que en la obra del autor "La representación literaria se hace cargo de la ausencia de certezas" (63).

${ }^{3}$ Hemos abordado en trabajos anteriores el alcance de conceptos como literatura testimonial o documental en el contexto latinoamericano (García, "Testimonio"). Baste decir aquí que, en rasgos generales, se trata de textos que toman distancia del pacto ficcional y se postulan como verídicos, a menudo con fines de denuncia social y política. Los textos testimoniales y documentales se inscriben, así, dentro del vasto territorio de las narrativas factuales, en los términos de Genette y Schaeffer. Remitimos a estos autores para un abordaje teórico de la oposición ficcional/factual, ampliamente debatida en el campo de los estudios literarios. 
conceptos adversarios seguían siendo verdad y mentira, para decirlo en términos muy simples.

[...] Bajo los puentes han pasado las aguas de Foucault y Derrida, los conceptos de narratividad y representación de Hayden White y hasta los ataques de Roland Barthes a la supuesta objetividad del discurso histórico tradicional. Pero sobre todo han pasado (o, más bien, han sucedido, nos han sucedido) el fracaso de los sandinistas en Nicaragua, la demolición del muro de Berlín, el estallido en fragmentos de la Unión Soviética, el atentado contra las Torres Gemelas y el Pentágono; nos están sucediendo todavía las crisis económicas engendradas por la globalización y los tambores de guerra contra Irak que Bush padre hizo sonar hace una década y que ahora regresan batidos por el hijo, casi con el mismo diapasón.

[...] Escribir no es ya oponerse a los absolutos, porque no quedan en pie los absolutos. ("Ficción" 14-15, subrayado en el original)

La primera persona que emerge en el relato -"nos han sucedido"- permite interpretar este pasaje como una mirada histórica que se posa no solo sobre la situación general de la literatura, sino especialmente sobre la obra del propio autor. En esta línea, Zuffi ha afirmado que desde un punto de vista diacrónico "la producción literaria de Martínez está signada por una pérdida de confianza en los conceptos abstractos de 'verdad', 'historia' y 'poder'” (32). En relación con el texto que nos ocupa, podemos decir que La pasión según Trelew se presenta en los años 2000 como el resto una concepción narrativa sustentada en la creencia en los absolutos, y en la confrontación militante entre lo verdadero y lo falso, que Martínez cultivó en los años 70, y que en la contemporaneidad se encuentra en crisis.

A continuación, nos proponemos estudiar el modo en que ese desplazamiento se inscribe en las sucesivas ediciones de La pasión según Trelew. Las diferencias que existen entre las ediciones del libro no han sido estudiadas de modo sistemático por la crítica, más allá de señalamientos aislados que es posible 
CATEDRAL TomAda: Revista de crítica literaria latinoamericana / Journal of Latin American Literary Criticism Del sonido del Pueblo a los ecos del pasado. Las versiones de La pasión según Trelew, de Tomás Eloy Martínez (1973-2009)

rastrear en algunos trabajos sobre el libro (Bonano 84-85, Zuffi 30, Chávez-Díaz, Neyret 8). El cotejo entre las distintas ediciones permitirá visualizar, en la línea que hemos expuesto hasta aquí, las soluciones que el autor adopta para actualizar un texto cuya concepción misma respondía a presupuestos que eventualmente llegó a considerar perimidos.

Organizaremos nuestra argumentación en tres partes, en las que abordaremos respectivamente las versiones del texto de 1973, 1997 y 2009. A través de un análisis de los cambios introducidos por el autor, tanto a nivel microtextual como de la organización general del material narrativo, podremos ver que las reescrituras tienden a diluir la confrontación entre verdad y mentira que inicialmente daba forma al relato de lo ocurrido en Trelew entre agosto y octubre de 1972 -fuga de los presos políticos del penal de Rawson, fusilamientos perpetrados contra algunos de los presos evadidos y posterior proceso de movilización popular desarrollado en Trelew ${ }^{4}$-. Asimismo, veremos que las reescrituras le restan protagonismo al Pueblo como sujeto colectivo que proveía fundamento a la confrontación entre verdad y mentira ordenadora del texto.

\section{En defensa de la verdad del Pueblo: la versión de 1973}

La pasión según Trelew se encuentra atravesado, desde su misma génesis, por la condición provisoria de la escritura, que en esta línea parece concebirse como un proceso abierto de construcción de versiones sobre una misma historia: en este caso, los hechos ocurridos en Trelew en 1972.

Inicialmente, Martínez abordó tales hechos en el semanario que entonces dirigía, Panorama. Lo hizo desde una perspectiva crítica hacia la dictadura comandada por Agustín Lanusse, que le valió su despido de la revista y el retiro de circulación del número dedicado a la masacre. "La aventura política que se inició el 28 de junio de 1966 tiene que llegar a su fin, porque la promesa de modernizar

\footnotetext{
${ }^{4}$ No podremos detenernos aquí en un racconto detallado de los acontecimientos narrados en el texto de Martínez. Para un enfoque historiográfico reciente de la fuga y los fusilamientos, véase Custer; sobre el llamado "Trelewazo", cfr. Ramírez, Binder y vid. infra, $§ 2$.
} 
el país se transformó en amenaza de terminar con todos los argentinos que no interpreten el 'estilo de vida' de determinados militares", concluía el artículo "Trelew: la sangre de los argentinos" (cit. en Neyret 10), publicado en el número 278 del semanario, cuya edición Martínez cerró en la misma madrugada del 22 de agosto en que ocurrieron los fusilamientos en la base aeronaval Almirante Zar. Esa versión inicial de los hechos, inacabada debido a la estricta actualidad de la materia histórica, pero sobre todo debido a la censura, constituyó el impulso inicial de un proceso de investigación y escritura que llevaría a la publicación del libro.

El autor realizó dos viajes a Trelew en octubre de 1972 y febrero de 1973. Allí recopiló material de prensa y se entrevistó con una veintena de personas involucradas en el proceso de movilización llamado Trelewazo. Este constituyó, como es sabido, la reacción popular ante el "Operativo vigilante" desplegado sobre esa ciudad, con el objetivo declarado de "proteger" a los habitantes de la región de los "elementos subversivos" que supuestamente se encontraban radicados allí y habían colaborado con la fuga de los presos políticos del penal de Rawson el 15 de agosto (Ramírez 54, Binder, "La Asamblea" 107). Luego de ese trabajo de investigación, Martínez comenzó a escribir el libro, según él mismo lo ha relatado (La pasión 13 [1973]), justo después de la asunción del gobierno de Héctor Cámpora, que tal como lo señala Pittaluga (86) abrió condiciones propicias para la proliferación de discursos de denuncia sobre los fusilamientos.

El libro apareció en agosto de 1973. Se presenta en sí mismo signado por un contrapunto entre versiones diferentes del relato de los hechos. En este sentido, el autor afirma en el prólogo:

En una primera versión, este libro fue una acumulación de crónicas, reportajes ajenos, discursos y documentos vinculados con la fuga del 15 de agosto, los fusilamientos de la base Almirante Zar y la movilización popular de octubre. Mi función iba a consistir en organizar las voces de aquel coro para que su sonido fuera el del Pueblo. La empresa era demasiado ambiciosa y exigía más tiempo del que estaba a mi alcance, y 
esa es la razón por la cual mis comentarios se entrometen en la historia con asiduidad excesiva. (Martínez, La pasión 12 [1973])

Llama la atención que, de acuerdo con estos señalamientos de Martínez, la selección y el montaje de materiales documentales para que "hablen por sí solos" sobre los hechos requieren mayor esmero compositivo y se dotan de un valor artístico superior al de la modalidad clásica del relato, en la que una voz narrativa toma a cargo la organización de la historia. Resuena aquí una puesta en valor del testimonio y el documento como formas de producción artística, característica de los debates del campo cultural del período (Gilman; García, "Testimonio”), y que pocos años antes había sintetizado Walsh en su entrevista con Ricardo Piglia: “evidentemente en el montaje, en la compaginación, en el trabajo de compaginación se abren inmensas posibilidades artísticas" (20). En el caso de Martínez, será la urgencia que parece revestir la denuncia de los hechos lo que lo llevará a dejar de lado la versión netamente documental del texto. Aun así, los materiales documentales compondrán una parte importante de la versión del libro aparecida en 1973, tanto en el cuerpo del texto como en un extenso segmento paratextual titulado "Apéndice de documentos".

El contrapunto entre distintas versiones del relato de los hechos es importante en La pasión según Trelew, además, en relación con el posicionamiento que el libro construye ante el discurso oficial sobre los fusilamientos. El texto busca evidenciar la inconsistencia y el carácter falaz de las explicaciones públicas que el régimen dictatorial ofreció sobre los sucesos, con versiones inverosímiles -como la que sostenía que los prisioneros habían intentado fugarse nuevamente- y hasta contradictorias entre sí ( $c f r$. Pittaluga 83). Ante tal intento de encubrimiento oficial, que se replicó en la mayoría de los medios de prensa, la denuncia de Martínez es contundente:

La mentira fue defendida y exaltada en cuanto diario o revista circuló por la Argentina durante las semanas que siguieron [...]. A la verdad no la 
publicaron todavía los diarios: circuló clandestinamente $[\ldots]$ en hojas mimeografiadas que distribuían los abogados de los combatientes, y solo después del triunfo peronista la reprodujeron semanarios como $E l$ Descamisado o Militancia y editores sueltos como e1 Foro por la Vigencia de los Derechos Humanos.

[...] De la mentira hubo cinco versiones oficiales o semi [...]. Es sabido que se contradicen entre sí. Que fueron urdidas por mentirosos que confiaban en su impunidad y que para apuntalarlas el régimen debió añadir un artículo (número 212) al Código Penal, amenazando con prisión a quien "por cualquier medio difundiere, divulgare o propagase comunicaciones o imágenes provenientes de, o atribuidas o atribuibles a asociaciones ilícitas o a personas o grupos notoriamente dedicados a actividades subversivas o de terrorismo" etcétera. (103-104 [1973])

Como se ve, la crítica de las falacias contenidas en el discurso oficial sobre la masacre se realiza a la par de una defensa abierta de los discursos contraoficiales, vinculados a la militancia de izquierdas y al proceso de movilización popular desarrollado en Trelew en octubre de 1972. De este modo, la dicotomía entre verdad y mentira que organiza el relato "se erige sobre una confrontación: ellos (milicos) frente a nosotros (pueblo), historia oficial (mentira)/ historia del pueblo (verdad)" (Zuffi 29). Dichas oposiciones antitéticas señalan la ubicación del narrador ante los hechos -que, así, dista de ser neutral-, y permiten dotar de sentido a la red heterogénea de materiales documentales que se incorporan el texto. A las versiones oficiales, transcriptas en el capítulo "Las cinco explicaciones militares" del apéndice documental, se contrapone una serie vasta de materiales diversos en su género -cartas, canciones, actas de asambleas, transcripciones de testimonios orales, entre otros-, que en conjunto configuran el "sonido del Pueblo" sobre los sucesos de Trelew, según lo define el autor en el prólogo (12 [1973]). ${ }^{5}$

${ }^{5}$ El contraste entre un discurso oficial cuya falacia se denuncia y un discurso contraoficial cuya verdad se defiende evoca, una vez más, a Walsh, sobre cuya literatura testimonial Martínez señaló 
CATEDRAL TomAda: Revista de crítica literaria latinoamericana / Journal of Latin American Literary Criticism Del sonido del Pueblo a los ecos del pasado. Las versiones de La pasión según Trelew, de Tomás Eloy Martínez (1973-2009)

La antítesis, así, es una figura central en la versión del libro de 1973. También lo son la sinécdoque y la prosopopeya. Estas intervienen en la configuración del Pueblo -así, con mayúsculas- como término positivo de la antítesis axiológicamente marcada entre verdad y mentira que organiza el texto, y como sujeto colectivo que protagoniza la historia. En primer lugar, la sinécdoque surge de la atribución del protagonismo en el libro a "la décima parte de la población total” de Trelew que se involucró en el Trelewazo (11 [1973]). Se trata, en términos de Laclau (97), de un procedimiento retórico característico de los procesos de subjetivación política: una parte asume la representación por una totalidad que la excede. En el libro de Martínez, en efecto, el sujeto colectivo Pueblo se construye a partir de un proceso de politización que tiene su origen en la llegada al penal de Rawson de "los Presos -así, a secas, como aprendieron a llamar en Trelew a los internados políticos--" (31 [1973]) y en los vínculos de solidaridad entre "los de Afuera y los de Adentro" (33) que se tejieron desde ese momento. ${ }^{6}$ La denominación que el autor recupera para referirse a los presos políticos de Rawson resulta significativa, pues contiene en sí un desplazamiento metonímico similar al que constituye al Pueblo como sujeto: el todo se dice por la parte en virtud de una condición política presupuesta ("los Presos" por "los presos políticos"). Asimismo, son relevantes las mayúsculas que también aquí emplea el autor, pues en todos los

en una entrevista de 1995: "Walsh en tanto trabaja sobre la denuncia tiene que trabajar sobre el bien y el mal. Son textos clara y admirablemente maniqueos" (cit. en Domínguez 30). La descripción de Martínez vale asimismo para La pasión según Trelew, aun cuando para este momento de su trayectoria el autor procure tomar distancia respecto del proyecto testimonial que Walsh impulsó en los años 60-70.

${ }^{6}$ Notemos que tanto el protagonismo conferido al Pueblo como la ubicación del punto cero de la historia política de Trelew en la llegada de los presos políticos al penal de Rawson forman parte de una construcción discursiva sobre el Trelewazo que trasciende la versión plasmada por Martínez en La pasión según Trelew. Como lo señala Ramírez, el sujeto Pueblo surge en y por el mismo proceso de movilización desarrollado en la ciudad, pues los actores involucrados se presentaron a sí mismos y definieron sus acciones y objetivos a partir de la pertenencia a una comunidad así denominada (67). Binder aporta, por su parte, que en la memoria popular sobre el Trelewazo este proceso se ha ubicado a menudo como "el íncipit de la narrativa histórica de los años 70 en la región [...], lo cual invisibilizó otras luchas y negó toda politización previa" ("Cuatro miradas" 106). 
casos se trata de entidades colectivas a las que se dota de nombre propio, como si se les confiriera estatus de personajes.

Esto nos lleva, en segundo lugar, al uso de la prosopopeya en el texto. Como ocurre en otros discursos históricos y políticos, el pueblo se configura aquí como "un colectivo dotado de [...] atributos de un ser humano, en el que se acentúa su carácter 'concreto', que permite asignarle autonomía” (Arnoux 75). En La pasión según Trelew, este procedimiento se aprovecha extensamente en su efecto estético. El mismo título del libro da cuenta de un procedimiento de cesión de la voz en el que "Trelew" aparece como nombre de un sujeto colectivo, y no solo como identificación toponímica. La atribución de rasgos humanos a ese topónimo permite enfatizar la vitalidad que adquirió la ciudad a partir del proceso de movilización allí desarrollado. De hecho, podría pensarse que existe una prosopopeya implícita en las denominaciones de todas las puebladas ocurridas en la Argentina entre $1969 \mathrm{y}$ 1972, en las que las ciudades -Córdoba, Rosario, Corrientes, Tucumán, Trelewaparecen a la vez como sedes y agentes del movimiento súbito, asociado a lo insurreccional, que indica el sufijo -azo.

A continuación, citamos algunos pasajes del libro en los que es posible apreciar el estatuto de personajes que adquieren conjuntamente el Pueblo y Trelew:

[...D]esde la mañana de aquel 11 de octubre, el pueblo de Trelew había paseado su indignación ante los edificios públicos, proclamó la huelga general y de estado de movilización permanente. Sobre las paredes del teatro Español, alguien había escrito Prohibido dormir. Y el pueblo obedecía. (Martínez 53 [1973]) ${ }^{7}$

Durante la semana que siguió a la masacre, Trelew enfermó de culpa.

Se había quedado de brazos cruzados cuando detuvieron a Mario Abel Amaya $[\ldots]$.

\footnotetext{
${ }^{7}$ Salvo indicación contraria, las cursivas son nuestras aquí y en todas las citas del texto de Martínez.
} 
CATEDRAL TomAda: Revista de crítica literaria latinoamericana / Journal of Latin American Literary Criticism

Del sonido del Pueblo a los ecos del pasado. Las versiones de La pasión según Trelew, de Tomás Eloy Martínez (1973-2009)

Había respetado a ciegas las ordenanzas del Comando de la Zona de Emergencia y se había callado la boca en las oficinas y en las colas de la feria $[\ldots]$.

Había respondido a los periodistas que invadieron el pueblo desde el 22 a la tarde: 'Yo no vi nada, yo no oí nada, yo no sé nada', porque lo tenían curado de espanto las molestias policiales a los apoderados, y la Marina cerca, y los Shortland en la calle.

Es verdad: la noticia de la masacre lo consternaba [...].

Se avergonzó de sí misma cuando uno de los vecinos opinó en Crónica, el 24 de agosto [...]. (141)

Al pueblo le importó más, sin embargo, una aldeana de negro que había luchado a brazo partido para que le dieran la palabra [...]. (149)

El pueblo ya estaba en otra cosa. (152)

El teatro se mareó de tanto aplaudir. $(151)^{8}$

El relato a cargo del narrador, así configurado, compone un marco que incorpora bajo las entidades colectivas de Trelew y el Pueblo las historias personales de quienes protagonizan la acción: testigos y partícipes del Trelewazo cuyas voces provienen de las entrevistas realizadas por el autor durante el proceso de investigación que condujo al libro. De esta forma, la voz del narrador oficia de instancia unificadora de las múltiples voces que habitan el texto. Si tal incorporación de diversas historias individuales a un itinerario colectivo es posible, es porque en el libro la elaboración literaria del material narrativo no se escinde de la construcción de una perspectiva política sobre los hechos. En efecto, la lógica de

${ }^{8}$ El narrador se refiere aquí al Teatro Español, donde se desarrollaron las asambleas durante los días del Trelewazo. De allí que la prosopopeya contenida en esta frase involucre un sentido de vivificación de un espacio físico derivado del proceso de movilización, igual que las personificaciones referidas a la ciudad de Trelew. 
la literatura emerge en la apelación a ciertos artificios figurativos -antítesis, sinécdoques, prosopopeyas que hemos analizado- como un principio constitutivo de la puesta en relato, y no meramente como una serie de elementos ornamentales adicionados al texto 9 . La lógica política, en tanto, surge en la medida en que el narrador se vale de tales elementos figurativos para potenciar la eficacia persuasiva del relato y, con ello, de la denuncia que despliega sobre el proceso represivo desarrollado en Trelew.

\section{Ecos del pasado: la versión de 1997}

En 1997, La pasión según Trelew fue reeditada con numerosos cambios introducidos por el autor. La reedición tuvo lugar en el contexto del boom de la memoria desplegado desde la segunda mitad de los años 90, cuando desde la sociedad civil se gestaron diversas prácticas y discursos que revitalizaron el pasado setentista y denunciaron los crímenes de Estado cometidos en aquella época, en respuesta a las políticas de impunidad iniciadas por el gobierno alfonsinista y consagradas por el menemista en la primera mitad de la década ( $c f r$. Crenzel 57$61)$.

La reedición ocurrió, a la vez, solo dos años después de la aparición de Santa Evita, que catapultó a Tomás Eloy Martínez al éxito nacional e internacional, y propició, con ello, la circulación de los libros anteriores del autor. De hecho, la nueva edición se publicó por la editorial Planeta, la misma que había publicado Santa Evita en 1995 y una reedición de La novela de Perón al año siguiente. En este contexto, la portada del libro de 1997 identifica a Tomás Eloy Martínez como "Autor de La novela de Perón y Santa Evita".

En "El prólogo de 1997", el autor reseña las modificaciones que ha realizado en el texto y en el paratexto del libro. Señala así que la nueva versión: "Suprime algunos documentos y discursos que duplicaban lo que ya se había

\footnotetext{
${ }^{9}$ Seguimos aquí a Todorov, quien observa la ligazón ineludible que existe entre lenguaje poético o literario y lenguaje figurado, ligazón que ha sido advertida en la reflexión teórica sobre las figuras desde la Edad Media en adelante (Ducrot y Todorov 321).
} 
CATEDRAL TomAda: Revista de crítica literaria latinoamericana / Journal of Latin American Literary Criticism Del sonido del Pueblo a los ecos del pasado. Las versiones de La pasión según Trelew, de Tomás Eloy Martínez (1973-2009)

narrado en el mismo libro de otra manera, y agrega revelaciones posteriores a 1973; a la vez, actualiza sustantivos y verbos coloquiales de aquella época que nada le dirían al lector de hoy” (Martínez 14 [1997]). Enseguida introduce la afirmación que citamos al comienzo sobre el extrañamiento que le suscita el libro en el momento de la reedición: “Aun así, La pasión según Trelew me parece la obra de otra persona, de alguien que ya no soy. Quizás escribimos sólo para ser otros” (14$15)$.

Aunque la descripción del autor sobre los cambios que se producen entre una y otra versión del libro es precisa, sólo un cotejo pormenorizado de sendas ediciones permite comprenderlos en toda su dimensión. A continuación, nos referiremos en detalle a estas variaciones, considerando en primer término las que intervienen en la organización general del material narrativo y, en segundo término, las que operan en el nivel local del texto.

\subsection{Cambios en la organización general del material textual}

Comencemos por las modificaciones que intervienen sobre la organización general del material narrativo. Como lo sugiere el autor en el prólogo, el centro de estas variaciones lo constituyen los segmentos documentales del libro. Tres tipos de cambios se registran en esta dirección:

a) El desplazamiento de documentos que en 1973 se encontraban en el apéndice al cuerpo del texto. Así ocurre en dos casos: los testimonios prestados en Puerto Belgrano por Ricardo Haidar, María Antonia Berger y Alberto Camps, sobrevivientes de los fusilamientos (cfr. Martínez 186 y ss. [1973] y 125 y ss. [1997]), y las explicaciones ofrecidas por el gobierno militar sobre la masacre tituladas "Las cinco explicaciones militares" en 1973 y "Las versiones oficiales" en 1997 (cfr. Martínez 198 [1973] y ss., y 147 y ss. [1997])-.

b) A la inversa, el desplazamiento al apéndice de documentos que en 1973 se encontraban en el cuerpo del texto. Así se observa en otros dos casos: la "Interpretación política de la masacre, hecha por fugitivos en Santiago de Chile" 
(Martínez 123 y ss. [1973]) -titulada en 1997 "Entrevista sobre la matanza, en Santiago de Chile" (211 y ss. [1997])-y los "Documentos que elaboró la Asamblea Popular en la noche del 11 al 12 de octubre para explicar su ideología y sus planes inmediatos de trabajo" (153 y ss. [1973]) -titulados en 1997 "Documentos de la asamblea popular de Trelew" (27 y ss. [1997])-.

c) La supresión in toto de documentos. Esto sucede en un caso en el cuerpo del texto, donde se omiten los testimonios pronunciados en el penal de Villa Devoto por Haidar, Berger y Camps (107 y ss. 1973]), y en otros ocho casos en el apéndice, de donde se eliminan por completo las siguientes piezas documentales: "Carta enviada por Rubén Pedro Bonet a sus hijos Hernán y Mariano el 26 de junio de 1972, cuando lo trasladaron del penal de Villa Devoto al de Rawson"; "Distinción otorgada al capitán de corbeta Luis Emilio Sosa por su participación en los fusilamientos de la Base Aeronaval 'Almirante Zar"'; "Respuesta de los jefes políticos de Trelew al cuestionario que les entregó El Chubut después de la liberación de los primeros diez detenidos"; "Párrafos del discurso pronunciado por el comandante de la Aviación Noval, capitán de navío Horacio Moyorga"; "La epopeya de Trelew" (narración publicada en el diario El Chubut), "Canción que compuso el pueblo de Trelew el 17 de octubre de 1972, tras la liberación de los primeros diez detenidos" y "Consignas del pueblo de Trelew durante los días de la movilización por los presos". Asimismo, en "Canciones que compuso el pueblo de Trelew entre el 11 y el 15 de octubre de 1972" se incluyen solo cuatro de las ocho canciones que aparecían en la edición de 1973.

En la misma línea, el epígrafe de la primera edición, de clara impronta documental: "LA SANGRE DERRAMADA NO SERÁ NEGOCIADA. Consigna voceada por los militantes peronistas durante las asambleas populares de 1972" (7 [1973]), se reemplaza en 1997 por un fragmento del poema "Del otro lado", de Francisco Urondo (9 [1997]).

El desplazamiento de documentos al apéndice y las supresiones in toto operan en un mismo sentido: en ambos casos se trata de restarle relevancia a los materiales documentales. En efecto, la versión de 1997 aparece como "depurada" 
CATEDRAL TomAda: Revista de crítica literaria latinoamericana / Journal of Latin American Literary Criticism Del sonido del Pueblo a los ecos del pasado. Las versiones de La pasión según Trelew, de Tomás Eloy Martínez (1973-2009)

de documentos si se la compara a la de 1973. De esta forma, el nuevo texto se distancia más radicalmente de la idea original que Martínez había concebido para el libro, en la que los documentos debían "hablar por sí solos” sobre los hechos.

A la vez, si bien la tendencia a la síntesis y las supresiones parecen predominar en el modo en que el autor reorganiza el material narrativo, especialmente en lo relativo al manejo de documentos, el texto se expande cuando se trata de incorporar información recabada con posterioridad a 1973. Esto ocurre en particular en el capítulo "Ensayo general”, que se agrega íntegro en la edición de 1997. Se trata de un relato centrado en la fotógrafa Diana D’Urbano, apoderada de uno de los militantes del Ejército Revolucionario del Pueblo presos en Rawson y testigo de un episodio que, según el autor, "acaso sirvió de ensayo general para la matanza" (35 [1997]). Sobre este relato, resultan significativos dos elementos: el primero es la caracterización del vínculo de la protagonista con su apoderado, en el que las posturas políticas de este último aparecen como un factor de desidentificación: "No estaba de acuerdo con sus ideas ni con sus luchas pero sentía compasión por él: un huérfano criado por una tía miope que le devolvía las cartas sin leerlas" (118). El segundo refiere a la impronta general del relato, que se centra en lo que pareció constituir una práctica militar de fusilamientos ejecutada sobre una colonia de gatos el día anterior a que ocurriesen los fusilamientos en la base aeronaval Almirante Zar. Lo siniestro de la escena y su fuerte carga simbólica colocan a este capítulo más cerca del cuento extraño y de terror que de la tónica fuertemente realista y de denuncia que despliega en rasgos generales La pasión según Trelew.

\subsection{Cambios a nivel microtextual}

Además de las modificaciones generales en la organización del material narrativo, la versión de 1997 contiene numerosos cambios en el nivel local del texto. No se trata de detalles de estilo insignificantes o azarosos, sino de variaciones que responden a factores sistemáticos. El principio básico de estas variaciones es la pretensión de actualizar el texto de acuerdo con el presente de su reescritura. 
El intento de actualización se realiza, en primer lugar, en términos netamente informativos, a través de la adición de datos históricos sobre el derrotero de los personajes posterior a 1973. Así se observa en el capítulo introductorio "Personajes en desorden de aparición", centrado en los protagonistas del Trelewazo, y en distintas notas al pie agregadas al texto (68, 93, 171 [1997]). ${ }^{10}$ En los pasajes informativos añadidos, es recurrente la alusión al modo en que los personajes atravesaron la agudización del proceso represivo en los años posteriores a la masacre de Trelew, en particular durante la dictadura militar de 1976-1983. ${ }^{11}$

En otros pasajes -los más relevantes para el análisis-, la actualización del texto trasciende la puesta al día histórica, cargándose de significación ideológica y política. En efecto, los presupuestos que en 1973 orientaban la interpretación de los hechos varían sustantivamente. Acerca de la pueblada desarrollada en Trelew, el autor de 1973 decía: "Trelew fue, en aquellos días, una Sociedad Nueva creada por un Hombre Nuevo" (12 [1973]). En 1997 va a afirmar, más sobriamente: “Trelew se transfiguró durante aquellos días" (18 [1997]). El proceso de escritura mismo, y las expectativas políticas que lo orientaron en el contexto del fin de la dictadura de Lanusse y el ascenso del peronismo al gobierno, adquieren una significación distinta. En 1973, el autor señalaba:

Comencé a escribir el libro el 26 de mayo, entusiasmado por el espectáculo de una revolución que parecía al abrigo de todo desgaste. Las cárceles estaban vacías de presos políticos; las puertas de la Casa de Gobierno permanecían abiertas para el pueblo y los vivas a Perón no cesaban en el trabajo ni en la intimidad de los dormitorios. Confiábamos entonces en que

\footnotetext{
${ }^{10}$ La adición de notas al pie es significativa no solo desde el punto de vista del contenido sino además en lo relativo a la forma. Su inserción en la nueva versión del texto conlleva un desdoblamiento de la instancia narrativa que tiende a exhibir la construcción del relato y a desnaturalizar su relación con la historia, tal como lo observaremos más adelante en relación con las irrupciones del yo del narrador en el texto (vid. infra). En esta línea, el uso de la nota al pie en La pasión según Trelew de 1997 no se diferencia sustancialmente de su empleo como comentario metanarrativo en La novela de Perón y Santa Evita. Cfr. a este respecto Minay 90-91.

${ }^{11}$ Véanse los relatos biográficos sobre Mario Abel Amaya (Martínez, La pasión 31-32 [1997]) y Elvio Ángel Bel (33-34), y las notas al pie sobre Marcos Osatinsky (69), Roberto Santucho (93) y Mariano Pujadas (171).
} 
los Represores serían juzgados públicamente y en que la lista de sus crímenes aparecería en los diarios que iba a escribir el pueblo [...]. (13 [1973])

Mientras que en 1997 dirá:

Comencé a escribir el libro el 26 de mayo, entusiasmado por el espectáculo de una democracia naciente que parecía al abrigo de todo desgaste. Las cárceles estaban vacías de presos políticos; las puertas de la Casa de Gobierno permanecían abiertas para la gente y los vivas a Perón - a quien se veía entonces como el portador de una paz definitiva-se oían hasta en la intimidad de los dormitorios. Millones de argentinos creían con ingenuidad que los jefes de la dictadura saliente serían juzgados en público y los diarios publicarían la lista de sus crímenes [...]. (19-20 [1997])

La revisión de la interpretación histórica tiende a la moderación y a la toma de distancia: la "revolución" pasa a ser la "democracia", se relativiza el entusiasmo en relación con la figura de Perón y, más aun, la historia deja de ser contada en primera persona, con un autor inserto en el colectivo del Pueblo ("Confiábamos entonces..."), a ser narrada en términos impersonales ("Millones de argentinos creían con ingenuidad...”). Se trata de una revisión anacrónica, que proyecta sobre la figura de autor de 1973 rasgos que pertenecen, en rigor, al autor de 1997. De hecho, estos pasajes corresponden al "Prólogo", que en 1997 pasa a titularse "El prólogo de 1973". Pese a esa indicación cronológica, el texto del prefacio es distinto del de la edición original. El anacronismo involucrado en las intervenciones del autor de 1997 resulta particularmente claro en la reformulación del pasaje referido al proceso de escritura que analizamos en el apartado anterior. Si, en 1973, el autor señalaba que originalmente se había propuesto organizar el material documental 
"para que su sonido [el del texto] fuera el del Pueblo" (12 [1973]), en 1997 en cambio afirma:

En una primera versión, este libro fue una acumulación de crónicas, reportajes ajenos, discursos y documentos vinculados con la fuga del 15 de agosto, los fusilamientos de la base Almirante Zar y con la movilización popular del mes de octubre. Me propuse tan sólo organizar las voces de aquel coro para que su sonido no traicionara el sonido del pasado. Pero el pasado nunca vuelve a ser lo que fue. El pasado es sólo una manera de no encontrarse con el presente. (18-19 [1997])

Evidentemente, los ecos de Trelew solo emergen como "sonido del pasado" en 1997, y no en 1973, cuando la masacre era un acontecimiento reciente y, más aun, los discursos públicos de denuncia sobre los hechos apenas comenzaban a desarrollarse. Este anacronismo puede leerse, en términos de Annick Louis, como una maniobra que el autor introduce sobre su propia obra: una manipulación del material textual que apunta a "la orientación e imposición de un conjunto de significados literarios" (Jorge Luis Borges 20) y, en este caso, también políticos, a la vez que busca reconfigurar la imagen de autor. En esta línea, la reformulación del prólogo instituye al pasado en el lugar ocupado por el Pueblo en la versión de 1973.

De hecho, podría decirse que el Pueblo como sujeto colectivo se deja en el pasado en la versión del libro de 1997, pues también en el cuerpo del texto pierde protagonismo. En algunos casos, el autor elige sustituir ese término por otro sustantivo colectivo menos marcado políticamente, la "gente":

i. [...D]esde la mañana de aquel 11 de octubre, el pueblo de Trelew había paseado su indignación ante los edificios públicos, proclamó la huelga general y de estado de movilización permanente. Sobre las paredes del 
CATEDRAL TOMADA: Revista de crítica literaria latinoamericana / Journal of Latin American Literary Criticism

Del sonido del Pueblo a los ecos del pasado. Las versiones de La pasión según Trelew, de Tomás Eloy Martínez (1973-2009)

teatro Español, alguien había escrito Prohibido dormir. Y el pueblo obedecía. (Martínez 53 [1973])

Desde la mañana del 11 de octubre, la gente de Trelew había paseado su indignación ante los edificios públicos, proclamó la huelga general y de estado de movilización permanente. Sobre las paredes del teatro Español, alguien había escrito Prohibido dormir. Y la gente obedecía. (63 [1997])

ii. El comunicado era excesivo, porque el pueblo no podía tener acceso a otras informaciones que las emitidas por fuentes oficiales. (139 [1973])

El comunicado era excesivo, porque la gente tenía acceso sólo las informaciones emitidas por fuentes oficiales. (173 [1997])

En otros casos, frases en las que el pueblo aparecía como sujeto son enteramente suprimidas:

iii. No entendía de dónde venía fluyendo la felicidad que entraba en él de golpe como jabón en el ojo: tardaría meses en darse cuenta que a lo mejor venía del pueblo, cuya sublevación comenzaba en ese momento sin que ellos lo supieran, o tal vez de las claras torpezas del enemigo, para quien cada argentino decente era un prisionero de guerra. (49 [1973])

No entendía de dónde venía fluyendo su repentina felicidad: tardaría meses en darse cuenta de que la felicidad-después me lo dijo-nacía de la paz de su conciencia. (59 [1997])

iv. Yo soy de La Laguna y ahí la gente tiene más mérito. Nosotros nunca aceptamos los colchones y las frazadas que andaba donando un ministro 
de la gobernación, y los del Norte sí los aceptaron. Somos más del pueblo que ellos. (159 [1973])

- Yo soy de La Laguna y ahí la gente tiene más mérito. Nunca aceptamos los colchones y las frazadas que fue a donarnos un ministro de la gobernación, y los del Norte sí los aceptaron. (192 [1997])

v. Al pueblo le importó más, sin embargo, una aldeana de negro que había luchado a brazo partido para que le dieran la palabra [...]. (149 [1973])

La revelación de la tarde fue, sin embargo, una campesina de negro que había luchado a brazo partido para que le dieran la palabra [...]. (184 [1997])

Al restarle presencia al pueblo como sujeto de la acción colectiva narrada en el libro, la versión de 1997 tiende a neutralizar la relación de identificación que el narrador mantenía con ese sujeto: así se aprecia especialmente en ejemplo (iv), donde la supresión afecta un pasaje en el que el pueblo aparecía asociado a caracteres manifiestamente positivos.

En la misma línea pueden comprenderse ciertas variaciones del texto relativas a la posición del narrador ante las organizaciones revolucionarias, que protagonizaron la fuga del penal de Rawson. La exaltación de la figura del “combatiente”, crucial en la militancia setentista, se atenúa, primero en el nivel del léxico, donde ese término es reemplazado sistemáticamente por otros como "militante" o "guerrillero". ${ }^{12}$ En un nivel semántico más general, se revisan pasajes que tendían a subrayar el "culto de la valentía, del coraje, del arrojo, del riesgo, de la hombría" (Longoni 162) ligado a aquella figura:

\footnotetext{
${ }^{12}$ Cfr. Martínez, La pasión 18, 49, 23, 24, 69, 70, 95 [1973] y Martínez, La pasión 31, 32, 27, 59, 84, 87, 115 [1997].
} 
CATEDRAL Tomada: Revista de crítica literaria latinoamericana / Journal of Latin American Literary Criticism

Del sonido del Pueblo a los ecos del pasado. Las versiones de La pasión según Trelew, de Tomás Eloy Martínez (1973-2009)

vi. En abril de 1971, durante una represión militar, cayeron muertos tres combatientes del ERP, entre ellos José Alberto Polti, hermano de Miguel Ángel. Este, a pesar de su juventud, asimiló con gran, madurez y entereza el duro golpe. (Martínez 18 [1973])

En abril de 1971, durante una represión militar, cayeron muertos tres militantes de su organización, entre ellos su hermano José Alberto. A Miguel le costó asimilar el golpe. (25 [1997])

vii. Para ellos, muchachos de sangre caliente, entregar las armas sin resistencia era una alternativa demasiado dura. Pero así lo habían acordado entre todos y nadie pensaba desentonar. (67 [1973])

Se dijeron una y otra vez que entregar las armas sin resistir era una alternativa demasiado dura. Pero así lo habían acordado entre todos. (81 [1997])

viii. Y allí se empezó a dar cuenta de que tendría que joderse y no morir [...], que debería acordarse de todo y correr a contarlo apenas pudiera. (103 [1973])

Se dijo entonces que no podía morir, que debía recordarlo todo y levantarse a contarlo apenas pudiera. (124 [1997])

Resulta significativo que, en el ejemplo (vi), la reformulación contradice la perspectiva del texto original ("asimiló con gran madurez y entereza el duro golpe" frente a "le costó asimilar el golpe"). Esto parece sugerir que la adecuación del texto al nuevo contexto y, sobre todo, a la figura de autor que encarna Martínez en 1997 se imponen incluso frente a la atención a los hechos, pues no resulta claro cuál 
de las dos versiones se ajusta más fielmente a la historia de Miguel Ángel Polti, a la que se refiere este fragmento.

El narrador que en 1973 no dejaba de posicionarse del lado de los guerrilleros en el antagonismo entre militares y Pueblo, en 1997 pasa a tomar distancia ideológica de las organizaciones revolucionarias. Esto es particularmente notorio en el capítulo "Personajes por orden de desaparición", que reseña la biografía de los guerrilleros fusilados en la base aeronaval Almirante Zar. En la versión de 1997, las caracterizaciones del accionar de la guerrilla dejan de lado las valoraciones positivas $\mathrm{y}$, en cambio, pasan a sugerir el carácter ilegal de sus métodos:

ix. Se destacó por su gran puntería con las armas y como instructora políticomilitar de los nuevos cuadros. (Martínez 16 [1973])

Se destacó como instructora político-militar de los nuevos cuadros. (28 [1997])

x.Participó en numerosas operaciones de expropiaciones de armas policiales, expropiación y reparto de alimentos a las villas miseria, tomas de fábricas y el fallido secuestro del general Julio Alsogaray. (17 [1973])

Participó en numerosas operaciones: robo de armas policiales, reparto de alimentos de las villas miseria, tomas de fábricas y el fallido secuestro del general Julio Alsogaray. (24 [1997])

xi. El 16 de noviembre [...] participó en la expropiación del Banco Comercial del Norte. (18 [1973])

El 16 de noviembre [...] participó en el asalto al banco Comercial del Norte. (25 [1997]) 
xii. Participó en la expropiación del Banco de Escobar, en enero de 1969. (973: 19 [1973])

Participó en el asalto al banco de Escobar en enero de 1969. (23 [1997])

La toma de distancia del narrador de 1997 frente a los acontecimientos políticos que son objeto del libro, y en especial frente a sus protagonistas, también se registra en el modo en que Trelew aparece representado en el relato. El carácter animado que adquiría la ciudad en el texto de 1973, a través del uso recurrente de la prosopopeya, se atempera en la nueva versión. Así, Trelew pasa de configurarse como héroe colectivo a entenderse más bien como una sumatoria de individuos, como lo sugieren los siguientes ejemplos:

xiii. En octubre de 1972 fui testigo del alzamiento popular con que Trelew respondió a la detención de dieciséis ciudadanos y al allanamiento de un centenar de casas de la región. (11 [1973])

En octubre de 1972 fui testigo del alzamiento popular con que los habitantes de Trelew respondieron al arresto de dieciséis ciudadanos y al allanamiento de un centenar de casas de la región. (17 [1997])

xiv. Durante la semana que siguió a la masacre, Trelew enfermó de culpa.

Se había quedado de brazos cruzados cuando detuvieron a Mario Abel Amaya [...].

Había respetado a ciegas las ordenanzas del Comando de la Zona de Emergencia y se había callado la boca en las oficinas y en las colas de la feria $[\ldots]$.

Había respondido a los periodistas que invadieron el pueblo desde el 22 a la tarde: "Yo no vi nada, yo no oí nada, yo no sé nada", porque lo tenían 
curado de espanto las molestias policiales a los apoderados, y la Marina cerca, y los Shortland en la calle.

Es verdad: la noticia de la masacre lo consternaba [...].

Se avergonzó de sí misma cuando uno de los vecinos opinó en Crónica, el 24 de agosto [...]. (141 [1973])

Nadie sabe cuándo ni por qué apareció en Trelew, después de la matanza, un sentimiento inexplicable de culpa. [...].

Se habían quedado de brazos cruzados cuando detuvieron a Mario Abel Amaya [...].

Habian obedecido como ovejas las ordenanzas del comando de la zona de emergencia y se habian callado la boca en las oficinas y en las colas de la feria $[\ldots]$.

Habian respondido a los periodistas que invadieron el pueblo desde el 22 a la tarde: "Yo no vi nada, yo no oí nada, yo no sé nada". Temían el rigor de la policía y de la marina. Temían a los tanques Shortland que patrullaban las calles.

La noticia de la masacre los había consternado [...].

Se avergonzaron de sí mismos cuando uno de los vecinos opinó en Crónica, el 24 de agosto [...]. (175-176 [1997])

En la misma línea puede leerse la supresión de las mayúsculas que en 1973 se utilizaban en las referencias a entidades colectivas o abstractas, como si se tratase de personajes: "los presos" (39 [1997]), "los de afuera y los de adentro" (41-42), “el poder” (48), dejan de tratarse como nombres propios en la edición de 1997.

La nueva versión suaviza así el tono intenso y enfático de la edición de 1973. Asimismo, los contrastes antitéticos que orientaban la interpretación de los hechos, derivados de la confrontación entre Pueblo y militares, tienden a reducirse en 1997. Es significativa en esta línea la eliminación in toto de un extenso pasaje referido críticamente al discurso oficial sobre los fusilamientos y, en particular, al 
CATEDRAL TomAda: Revista de crítica literaria latinoamericana / Journal of Latin American Literary Criticism

Del sonido del Pueblo a los ecos del pasado. Las versiones de La pasión según Trelew, de Tomás Eloy Martínez (1973-2009)

esquema de pensamiento "blanco/negro" que dicho discurso sostenía, según el narrador de 1973:

Era el lenguaje típico de los cazadores de brujas, que [...] habían impuesto el desorden con el pretexto de garantizar el orden o -como el contraalmirante Hermes Quijada seis semanas atrás- habían caracterizado a las fuerzas represoras y a los combatientes de la guerrilla según el esquema blanco/negro a que se atuvo siempre el pensamiento primitivo cuando lo afligían la incertidumbre o la culpa. Un periodista anónimo había resumido en estos cuadros explicativos el discurso con que Quijada intentó explicar la masacre:

Nosotros Ellos

Comunidad democrática. Grupos minoritarios y fanatizados.

Abnegados policías y servidores Agentes del odio y la subversión.

públicos.

Terroristas.

Inocentes ciudadanos. Delincuentes.

Víctimas.

Asesinos.

Deudos, viudas, huérfanos.

De tales fisonomías se desprendían naturalmente estas conductas:

Nosotros

Tradición histórica de principios e ideales.

Vivir en paz y en justicia forjando una nación.

Honor y dignidad.

Valor y empuje
Ellos

muerte, alimentada por una ideología atea y materialista.

Destrucción e intimidación general.

Barbarie.

Odio desatado (Martínez, 142-143

[1973], subrayado en el original). 
Los binarismos y la confrontación política entre nosotros y ellos, que en este pasaje se adjudican al discurso oficial sobre la matanza, no dejaban de orientar en 1973 el discurso del propio narrador, aun cuando el contenido conceptual y axiológico asociado a cada uno de los términos se invirtiera -tal como lo hemos señalado en el análisis de la primera edición-. De allí que, en 1997, este fragmento sea eliminado por completo.

Del mismo modo, la oposición entre verdad y mentira, que en 1973 organizaba el relato, se relativiza en 1997. Otra supresión in toto es relevante aquí: la del pasaje que citamos en el apartado precedente, donde se contraponían las falsedades del discurso oficial a la veracidad de las versiones contraoficiales sobre la masacre: "La mentira fue defendida y exaltada en cuanto diario o revista circuló por la Argentina [...]. A la verdad no la publicaron todavía los diarios [...]" (103104 [1973] y vid. supra, § 2). Asimismo, los términos "verdad" y "mentira" tienden a desusarse en la edición de 1997, como se ve en los siguientes ejemplos de supresiones y sustituciones:

xv. Y el pueblo no estaba dispuesto a que nadie se tragara la mentira. (11 [1973])

Y el pueblo no iba a tolerar que se difundiera esa falsía. (17 [1997])

xvi. Entre agosto y noviembre de 1972, los sobrevivientes narraron dos veces su odisea.

[...] Ambas narraciones coinciden en los detalles, pero la segunda es más minuciosa. Los historiadores tendrán que atenerse a ella para establecer:

LA VERDADERA HISTORIA DE LO QUE PASÓ EN LA BASE ALMIRANTE ZAR EL 22 DE AGOSTO. (106-107 [1973])

Dos veces [Berger, Camps y Haidar] narraron sus odiseas. 
CATEDRAL TomAda: Revista de crítica literaria latinoamericana / Journal of Latin American Literary Criticism

Del sonido del Pueblo a los ecos del pasado. Las versiones de La pasión según Trelew, de Tomás Eloy Martínez (1973-2009)

[...]. Ambas narraciones coinciden hasta en los detalles, pero la segunda es más minuciosa. Una y otra tienen el insoportable -y en este caso insoslayable- lenguaje de los documentos judiciales. (124-125 [1997])

xvii. $\quad$-¿Notó usted un verdadero sentimiento de unidad popular? (167 [1973])

- ¿Le pareció que todos estaban de acuerdo? (200 [1997])

xviii. Lo más intolerable, sin embargo, era el comunicado mentiroso del V Cuerpo que estaban difundiendo por la radio [...]. (142 [1973])

Lo que más los ofendió, sin embargo, fue el comunicado del V Cuerpo que estaban difundiendo por la radio [...]. (176 [1997])

Estas variaciones, relevantes desde el punto de vista ideológico, tienen implicaciones propiamente literarias, pues dan cuenta de una revisión de los presupuestos conceptuales en los que se sostiene una literatura que busca dar cuenta de los hechos, como la que despliega La pasión según Trelew. La relativización de los conceptos de verdad y mentira que se observa en la edición de 1997 lleva aparejada, en este sentido, una irrupción más frecuente de la subjetividad del narrador en el relato: ${ }^{13}$

xix. Chiche contará que los hombres se movían con incomodidad y desconfianza, como si se les hubieran desclavado las suelas de los zapatos. (34 [1973])

${ }^{13}$ La relación entre la apelación a la primera persona y la pérdida de confianza en la idea de verdad, asociada a las limitaciones del lenguaje para representar lo real, se explicita en el ensayo "El miedo de los argentinos", de 1996: "La primera persona es útil cuando se ha perdido la fe en la eficacia de las palabras, como ocurre con la mayoría de nosotros" (Martínez, Las memorias 150). 
Chiche me contó que los hombres se movían con incomodidad y desconfianza, como si se les hubieran desclavado las suelas de los zapatos. (43-44 [1997])

xx. "Llevo una vida de hogar y de trabajo -dirá un mes más tarde-[...]". (44 [1973])

"Llevo una vida de hogar y de trabajo -me diría un mes más tarde[...]". (53 [1997])

xxi. "Me cambiaron -contará después- [...]”. (44 [1973])

"Me cambiaron -iba a contarme después- [...]". (53 [1997])

xxii. No entendía de dónde venía fluyendo la felicidad que entraba en él de golpe como jabón en el ojo: tardaría meses en darse cuenta que a lo mejor venía del pueblo [...]. (49 [1973])

No entendía de dónde venía fluyendo su repentina felicidad: tardaría meses en darse cuenta de que la felicidad -después me lo dijo- nacía de la paz de su conciencia. (59 [1997])

xxiii. Trabajo para los milicos, como dije, en la Dirección de Automotores [...]. $(60$ [1973])

Ya te dije que trabajo para los militares. Soy chofer en la Dirección de Automotores [...]. (72 [1997])

xxiv. "Nos dimos cuenta de lo torpes que habíamos sido entre el 15 y el 22 de agosto -dirá Chiche...”. (145 [1973]) 
"Nos dimos cuenta de lo torpes que habíamos sido entre el 15 y el 22 de agosto -me diría después Chiche...". (178 [1997])

Como se ve en los ejemplos, el narrador emerge en la edición de 1997 como un partícipe activo del proceso de (re)construcción de la historia. Se trata, en esta línea, de irrupciones del "personaje" del autor que intervienen en un nivel metaliterario, pues ponen en escena la trama de investigación y escritura que sostiene la configuración del relato. Una vez más, la nueva versión del texto contraría la idea original que el autor había tenido para el libro. Así, lejos de entenderse como una "intromisión excesiva" frente al privilegio del material testimonial y documental -como se formulaba en el prólogo de 1973-, la figura del narrador aparece como un elemento productivo del relato. No solo porque desnuda los entretelones de la puesta en discurso y porque, en este sentido, su exhibición podría resultar hasta más veraz que una narración despersonalizada o pretendidamente objetiva. Sino, sobre todo, porque instituye una dimensión específicamente literaria del texto, al otorgar relevancia al hecho que, más allá de los acontecimientos de la Historia, constituye la escritura como actividad creativa.

Para terminar este apartado, nos concentraremos en un último aspecto de la edición de 1973, relacionado con la dimensión específicamente literaria de las variaciones introducidas por el autor. Nos referimos al hecho de que Martínez interviene no solo sobre el discurso del narrador, sino además sobre el de los personajes. Tratándose de un libro documental o testimonial, esto resulta particularmente significativo, pues se trata de alteraciones operadas sobre una materia textual que se presenta como transcripción o cita literal de los testigos entrevistados por el autor. Veamos a continuación algunos ejemplos:

xxv. Eran médicos, abogados, periodistas, profesores, escribanos, arquitectos y empleados públicos que se habían cansado de deslomarse solo para ganar la admiración de los amigos (o que habían fracasado en el intento y no 
querían repetirlo), para afincarse en “este paraje ideal -como diría más tarde Celia Negrín-, donde vivimos sin familia pero llenos de amigos". (30 [1973])

Eran médicos, abogados, periodistas, profesores, escribanos, ·arquitectos y empleados públicos que se habían hartado de hacer méritos sólo para ganar la admiración de los amigos (o que habían fracasado en el intento y no querían repetirlo). "Este paraje es ideal", diría más tarde Celia Negrín. "Vivimos sin familia, pero también sin pasado. Al entrar aquí nos pusimos otro cuerpo”. (38 [1997])

xxvi. El policía de civil se aplicó con interés al examen de unos sobres en los que guardaba trabajos de investigación lingüística. Uno lo apasionó particularmente: era [...] sobre En la colonia penitenciaria, el cuento de Franz Kafka [...].

Cuando terminó la requisa, el hombre de civil tomó el sobre y volvió a leer las hojas, esta vez atentamente. Le pregunté si se las llevaría. Me dijo que le explicara de qué se trataba. Lo hice.

- ¿Tiene que suceder en una cárcel? - preguntó el policía.

- Es una casualidad - contesté, afligida. (46-47 [1973])

El policía de civil se aplicó con interés al examen de unos sobres en los que guardaba trabajos de investigación lingüística. Uno lo apasionó particularmente: era [...] sobre En la colonia penitenciaria, el cuento de Franz Kafka [...].

Cuando terminó la requisa, el hombre de civil tomó el sobre y volvió a leer las hojas, esta vez con mucha atención. Le pregunté si las necesitaba. Quiso que le explicara de qué se trataba. Lo hice. Es una historia de Kafka, le dije. La historia de un soldado que ha insultado a un oficial y que es 
CATEDRAL TomAda: Revista de crítica literaria latinoamericana / Journal of Latin American Literary Criticism

Del sonido del Pueblo a los ecos del pasado. Las versiones de La pasión según Trelew, de Tomás Eloy Martínez (1973-2009)

condenado a morir desangrándose. Sobre su cuerpo, escribe la sentencia: DEBES HONRAR A TUS SUPERIORES.

- $\quad$ ¿Sucede en una cárcel? - preguntó el policía.

- $\quad$ No se sabe -contesté, preocupada-. Están en un valle arenoso, rodeado por rocas desnudas.

- $\quad$ Como aquí, me dijo.

- $\quad$ Casi como aquí. Es una casualidad. (56-57 [1997])

xxvii. Diga si su nombre es Gustavo Adolfo Peralta -ordenaba el oficial, afuera o en la carpa de al lado.

-Me llamo Fidel Gustavo Peralta -contestaba Gustavo.

-No, Gustavo Adolfo -decidía el oficial. -Si usted quiere que me llame Gustavo Adolfo, está bien, no tengo inconveniente. Pero complicaríamos las cosas. Me anotaron como Fidel Gustavo en el Registro Civil. (48-49 [1973])

- Diga si su nombre es Gustavo Adolfo Peralta -ordenaba el oficial en alguna parte, quizás en la carpa de al lado.

-Me llamo Fidel Gustavo Peralta -contestó Gustavo.

-No, Gustavo Adolfo -decidió el oficial.

-Si usted quiere que me llame Gustavo Adolfo, está bien, no tengo inconveniente. Eso me permitiría volver con las oscuras golondrinas. Pero no es así. Me anotaron como Fidel Gustavo en el Registro Civil. (58-59 [1997])

Como se ve en los pasajes subrayados de los ejemplos, las modificaciones implementadas sobre el discurso de los personajes en 1997 tienden a acentuar la dimensión metafórica del texto, pero además incorporan o amplían referencias literarias (Kafka, Bécquer) para explorar formas de la intertextualidad que estaban ausentes en la edición de 1973. Si, una vez más, el cotejo de ambas versiones del 
texto puede sembrar dudas sobre cuál de ellas da cuenta fielmente del relato de los protagonistas, en rigor la propia reescritura da la pauta de que no es esto lo que orienta al autor a la hora de reescribir: el texto que prevalece es el más eficaz desde el punto de vista estético, y no necesariamente el que se ajusta de forma rigurosa a la realidad del material testimonial sobre cuya base se construyó La pasión según Trelew.

\section{Una obra de otra persona: la versión de 2009}

La reedición de 2009 se inscribe dentro de una nueva etapa en lo relativo a las políticas de memoria en la Argentina: el momento de estatalización (Crenzel 61), desplegado a partir de una serie de iniciativas gubernamentales iniciadas en 2003 durante la presidencia de Néstor Kirchner, que llevarían a la reapertura de los procesos jurídicos sobre los crímenes de Estado perpetrados durante la década de 1970 y, más en general, situarían el llamado "pasado reciente" en un lugar central de los discursos y prácticas de gobierno.

En este contexto, el reinicio de la investigación sobre los fusilamientos del 22 de agosto de 1972 dio lugar a un nuevo acercamiento de Martínez a los hechos y al proceso de investigación ligado al libro: en 2007 el autor fue citado a declarar en sede judicial. Si los avances oficiales en el esclarecimiento de los sucesos "reclamaban una minuciosa puesta al día” del texto, como señala Martínez en el prólogo de la edición de 2009 (La pasión 19), no será él, sin embargo, que lleve adelante esa actualización. En cambio, el autor delega la tarea en la periodista Susana Viau, al concederle la elaboración de un epílogo titulado "El regreso de los hechos", que aborda la situación en el presente de la reescritura de algunos de los protagonistas de los acontecimientos: militares involucrados en la matanza y

partícipes del Trelewazo. De esta forma, la edición de 2009 materializa la definición que en 1997 el autor había propuesto sobre el texto: La pasión según Trelew se vuelve aquí, efectivamente y ya no solo en un plano simbólico, un libro de otra persona. 
El autor, de hecho, opera pocos cambios en la versión de 2009. Además de la actualización del prólogo, que explica las motivaciones de la reedición, introduce algunos ajustes en el nivel microtextual que, en su mayoría, responden a factores similares a los que observamos en la edición de 1997: inserta información histórica concerniente a la trayectoria de los personajes posterior a 1973 -especialmente en el capítulo "Personajes que reaparecieron", centrado en los tres sobrevivientes de los fusilamientos (cfr. Martínez, La pasión 29-30 [1997] y Martínez, La pasión 3132 [2009])-, e interviene esporádicamente a nivel de la frase para descartar una vez más, las referencias al pueblo y a lo popular:

i. $\quad$ En 1987 regresé a Trelew para reencontrarme con los protagonistas del alzamiento popular en el Viejo teatro Español, donde habíamos cenado todos juntos en días más aciagos. (15 [1997])

Delegar la historia me ha permitido también proteger el recuerdo de Trelew con el que quiero quedarme para siempre: el de mi viaje de 1987, cuando me reencontré con los protagonistas del alzamiento civil en el Viejo teatro Español, donde habíamos cenado todos juntos en días más aciagos (Martínez, La pasión 20 [2009]).

ii. Trelew había tolerado hasta entonces, con cierto sentimiento de culpa, que los militares supusieran que el pueblo era tibio y prudente, pero acusarlos de colaborar pasaba de la raya. (46 [1997])

Trelew había tolerado hasta entonces, con cierto sentimiento de culpa, que los militares supusieran que los habitantes eran tibios y temerosos, pero acusarlos de colaborar pasaba de la raya. (47 [2009])

iii. Enronquecieron cantando el himno, convocando a la huelga general e inventando consignas como: 
Con la lucha popular

a los presos liberar

$\mathrm{y}$

El pueblo unido

jamás será vencido. (159 [1997], subrayado en el original)

Enronquecieron cantando el himno, convocando a la huelga general e inventando consignas como:

Con la lucha popular

a los presos liberar. (179 [2009], subrayado en el original)

En cuanto al epílogo de Susana Viau, este aborda la actualidad de los fusilamientos de 1972, atravesada por el proceso judicial sobre los hechos, en tres partes sucesivas: "El proceso en proceso", centrada en los militares imputados, "El living de Trelew", enfocada en habitantes o exhabitantes de Trelew que tomaron parte en el proceso de movilización allí desarrollado, y "Epílogo provisional”, que esboza una conclusión provisoria del relato. La segunda parte resulta particularmente relevante para el análisis, pues se expone allí la distancia histórica desde la que se miran los sucesos ocurridos en Trelew en 1972 y, más en general, el proceso social y político de los años 70. Los relatos que componen esta parte abordan las trayectorias biográficas ulteriores de los partícipes del Trelewazo que protagonizan el libro. En sus historias, este acontecimiento aparece como la manifestación más intensa de un proceso de politización que, a posteriori, se ha revertido o disuelto: "Las [discusiones] que nos interesaban están terminadas. Al menos por un tiempo", declara Chiche López (268 [2009]), mientras que su esposa Margarita García señala: "me quedé prendida en una época que pasó" (269). Sobre Isidoro Pichilef, la narradora afirma que "no es más peronista" (264), y sobre Elisa Martínez cuenta que "Su aspiración a cambiar el mundo quedó circunscripta al ámbito académico" (278). 
CATEDRAL TomAda: Revista de crítica literaria latinoamericana / Journal of Latin American Literary Criticism Del sonido del Pueblo a los ecos del pasado. Las versiones de La pasión según Trelew, de Tomás Eloy Martínez (1973-2009)

Así, el postfacio alógrafo de la edición de 2009 consolida los desplazamientos de sentido que el mismo autor había introducido en el libro a partir de 1997. El Pueblo que protagonizaba el texto en un comienzo se disuelve en una multiplicidad de historias -las de "la gente" o "los habitantes de Trelew"- que tienen en común un pasado y no ya un horizonte de futuro. Se trata, no obstante, de un proceso que permanece abierto, tal como lo sugiere el calificativo de "provisional” que Viau añade a su epílogo. La sentencia judicial por los fusilamientos de la base aeronaval Almirante Zar llegaría tres años después de la reedición, en 2012. Tomás Eloy Martínez no pudo atestiguarlo, pues falleció en 2010.

\section{Conclusiones}

La pasión según Trelew se configura, desde su misma génesis, a partir de un entramado de versiones diferentes sobre los hechos ocurridos en esa ciudad en 1972. Si inicialmente se trataba de confrontar las versiones desde una perspectiva política, oponiendo la verdad del pueblo a las mentiras del poder militar, más tarde esa confrontación se relativizará, a la vez que resultará desarticulado o debilitado el sujeto colectivo que solía sostenerla. En efecto, el autor que en un comienzo se había propuesto hacer a hablar al "coro del Pueblo", dejará de lado eventualmente esa búsqueda, de modo tal que, para 1997, será el Pasado que pase a ocupar el lugar de aquel "personaje" supraindividual -en el contexto del boom de la memoria la segunda mitad de los años 90-. Para 2009, el desplazamiento será más rotundo: no sólo no será el autor quien lleve adelante la puesta al día del libro -en el marco de la revitalización de la memoria sobre Trelew favorecida por la reapertura del proceso judicial-, sino que además las voces que se incorporen al texto serán las de los protagonistas del Trelewazo ahora ajenos a identidades colectivas, distanciados de la participación política y privados de horizontes de cambio social radical.

Las variaciones introducidas por el autor en las ediciones de 1997 y 2009 de La pasión según Trelew no constituyen meros detalles de estilo insignificantes o azarosos, sino que contienen una indudable significación ideológica y política. 
Más aun, poseen implicaciones literarias, en la medida en que exponen desplazamientos en el modo en que el autor concibe la relación entre historia y relato, entre los hechos y su (re)elaboración narrativa. En esta línea, hemos visto cómo el texto se aparta progresivamente de una concepción documentalista, según la cual los materiales recopilados en el proceso investigativo debían hablar "por sí solos" sobre los acontecimientos, y llega a dar vía libre a la irrupción de un narrador que se descubre como pieza ineludible en la reconstrucción de la historia. La subjetividad, así, pasa a constituir un principio constitutivo de la verdad que el autor despliega sobre la masacre, una verdad que, a su vez, se asume más abiertamente como versión posible sobre los hechos -y no ya como la verdad, opuesta tajantemente a los engaños del poder-. Asimismo, hemos observado que algunos de los cambios efectuados por el autor desatienden la condición factual del relato, al fundamentarse en un criterio estético, y no necesariamente en la fidelidad del texto a los hechos o a la palabra de los testigos.

Es que, si como lo señala el narrador de Santa Evita "Todo relato es, por definición, infiel” (Martínez, Santa Evita 97), entonces las distintas versiones de la historia ya no podrán concebirse como enfrentadas según la dicotomía entre verdad y mentira. El flujo de las versiones continuará en la medida en que la historia permanece abierta, con sus resonancias en el presente -incluso más allá de la última edición del libro-, y será la lógica interna del relato -la de la literatura- la que permita dirimir "con cuál versión quedarse", como también dice el narrador de la más célebre novela del autor (146). Ante la crisis de los absolutos, Tomás Eloy Martínez responde con una apuesta por la literatura, aun cuando ello suponga revertir un proceso de politización que había alcanzado su clímax en el Trelewazo y en las puebladas de los años 60-70. 


\section{Bibliografía}

Arnoux, Elvira. "La construcción del objeto discursivo 'el pueblo de la plaza pública' en la Historia de Belgrano y de la Independencia argentina de Bartolome Mitre. Análisis del discurso. Modos de abordar materiales de archivo. Santiago Arcos, 2009, pp. 65-93.

Binder, Axel. 'Cuatro miradas sobre el 'Trelewazo'. Memorias en torno a una experiencia de lucha popular". Historias detrás de las memorias. Un ejercicio colectivo de Historia Oral, editado por Patricia Flier, Universidad Nacional de La Plata- FAHCE, 2018, pp. 101-134.

. "'La Asamblea les pasó por arriba': represión, mediación política y acción directa en el Trelewazo (1972, Chubut)". Conflicto social vol. 12, no. 22, 2019, pp. 103-133, https://publicaciones.sociales.uba.ar/index.php/CS/article/view/5166/430 1 , consultado el 26 de octubre de 2020.

Bonano, Mariana. "La escritura testimonial y las memorias de Trelew en $L a$ patria fusilada de Francisco Urondo y La pasión según Trelew de Tomás Eloy Martínez". Telar. Revista del Instituto Interdisciplinario de Estudios Latinoamericanos nos. 2-3, 2005, pp. 75-92, http://revistatelar.ct.unt.edu.ar/index.php/revistatelar/article/view/245, consultado el 20 de octubre de 2020.

Chávez Díaz, Liliana. "Recordar, registrar y reescribir. La entrevista periodística en La pasión según Trelew de Tomás Eloy Martínez". América. La chronique latino-américaine 19e-21e siècles, vol. 1, no. 48, 2016, doi: 10.4000/america.1559.

Crenzel, Emilio. "Entre la historia y la memoria. A 40 años del golpe de Estado en la Argentina", História: Questões \& Debates, vol. 2, no. 64, 2016, pp. 39-69, doi: 10.5380/his.v64i2.49733.

Custer, Carlos. "Reconsiderando la masacre de Trelew. Entre el ocaso de la Revolución Argentina y la institucionalización democrática". Izquierdas no. 43, 2018, pp. 209-236, doi: 10.4067/S0718-50492018000600209.

Domínguez, Nora. "El cuerpo de Eva es el cuerpo de la Argentina”, Página/12, 16 de julio de 1995, pp. 30-31.

Ducrot, Oswald y Tzvetan Todorov. Diccionario enciclopédico de las ciencias del lenguaje. Siglo Veintiuno, 1974.

Ferro, Roberto. El lector apócrifo. De la Flor, 1998.

García, Victoria. "Testimonio literario latinoamericano. Una reconsideración histórica del género". Exlibris. Revista del Departamento de Letras no. 1, 2012, pp. 371-389, http://revistas.filo.uba.ar/index.php/exlibris/article/view/422, consultado el 10 de octubre de 2020. . "Las reescrituras de Operación masacre". Estudios filológicos no. 63, 2019, pp. 23-44, 
http://revistas.uach.cl/index.php/efilolo/article/view/5583, consultado el 21 de septiembre de 2020.

Genette, Gérard. Fiction et diction. Seuil, 1991.

Gilman, Claudia. Entre la pluma y el fusil. Debates y dilemas del escritor revolucionario en América Latina. Siglo Veintiuno, 2012.

Hernaiz, Sebastián. Rodolfo Walsh no escribió Operación masacre y otros ensayos. 17grises, 2012.

Laclau, Ernesto. La razón populista. Fondo de Cultura Económica, 2005.

Longoni, Ana. Traiciones. La figura del traidor en los relatos acerca de los sobrevivientes de la represión. Norma, 2007.

Louis, Annick. Jorge Luis Borges. Obra y maniobras. Universidad Nacional del Litoral, 2014.

. ¿Por qué escribir un libro? Las versiones de Operación masacre de Rodolfo Walsh". Exlibris. Revista del Departamento de Letras no. 5 , 2016, pp. 394-409, http://revistas.filo.uba.ar/index.php/exlibris/article/view/3033, consultado el 8 de octubre de 2020.

Martínez, Tomás Eloy. La pasión según Trelew. Granica, 1973. . Santa Evita. Planeta, 1995. . Las memorias del General. Planeta, 1996. . La pasión según Trelew. Planeta, 1997. . "Ficción, historia y periodismo: límites y márgenes". Telar. Revista del Instituto Interdisciplinario de Estudios Latinoamericanos, vol. 1, no. 1, 2004, pp. 7-16, http://revistatelar.ct.unt.edu.ar/index.php/revistatelar/article/view/257, consultado el 1 de octubre de 2020.

. La pasión según Trelew. Alfaguara, 2009.

Minay, José. Recuperando a los Perón: Posmodernidad e intertextualidad en dos obras de Tomas Eloy Martínez. 2005. Universidad de Tennesse, tesis de doctorado. TRACE, trace.tennessee.edu/utk_graddiss/2672.

Neyret, Juan Pablo. "El valor del testimonio y el testimonio del valor: La pasión según Trelew de Tomás Eloy Martínez". Derecom no. 1, 2016, http://www.derecom.com/secciones/articulos-de-fondo/item/101-elvalor-del-testimonio-y-el-testimonio-del-valor-la-pasion-segun-trelewde-tomas-eloy-martinez, consultado el 3 de octubre de 2020.

Piglia, Ricardo. "Hoy es imposible en la Argentina hacer literatura desvinculada de la política" (Reportaje de Ricardo Piglia a Rodolfo Walsh / marzo de 1970). Walsh, Rodolfo. Un oscuro día de justicia. Siglo Veintiuno, 1973, pp. 9-28.

Pittaluga, Roberto. "La memoria según Trelew". Cuadernos del CISH nos. 19-20, 2006, pp. 81-111. SEDICI, http://sedici.unlp.edu.ar/handle/10915/13579, consultado el 3 de octubre de 2020.

Puente, Marta y Ana Davis. "La evolución ideológica de Rodolfo Walsh a través de las ediciones de Operación Masacre". Catedral Tomada vol. 8, no. 14, 2020, pp. 186-220, doi: 10.5195/ct/2020.447. 
CATEDRAL TOMADA: Revista de crítica literaria latinoamericana / Journal of Latin American Literary Criticism

Del sonido del Pueblo a los ecos del pasado. Las versiones de La pasión según Trelew, de Tomás Eloy Martínez (1973-2009)

Ramírez, Ana Julia. "Las mediaciones locales de la protesta: el caso del Trelewazo (octubre de 1972)". Sociohistórica no. 19-20, 2006, pp. 4780. SEDICI, http://www.sociohistorica.fahce.unlp.edu.ar/article/view/SHn1920a03/1719, consultado el 10 de octubre de 2020.

Schaeffer, Jean-Marie. "Fictional vs. factual narration". The living handbook of narratology, editado por Peter Hühn et al, Hamburg University Press, 2013, https://www.lhn.uni-hamburg.de/node/56.html, consultado el 7 de diciembre de 2020.

Historias detrás de las memorias. Un ejercicio colectivo de Historia Oral, editado por Patricia Flier, Universidad Nacional de La Plata- FAHCE, 2018, pp. 101-134.

Vincenti, Roberto. Crímenes y pecados: desbordes del relato de no ficción en la literatura argentina. 2015. Universidad de Buenos Aires, tesis de maestría. Repositorio Filo, repositorio.filo.uba.ar/handle/filodigital/4284.

Zuffi, María Griselda. Demasiado real: Los excesos de la historia en la escritura de Tomás Eloy Martínez (1973-1995). Corregidor, 2007. 